\title{
Emptying Śūnyatā: a Critical Reading of Nishitani's Religion and Nothingness
}

Abstract: In this article, invoking some terms of phenomenology and general principles of structural semiotics, I critically examine and reveal some aporetic aspects of Nishitani's interpretation of Buddhist concept of sūnyatā presented in his seminal work Religion and Nothingness. My critics are directed to deeply ingrained claims among scholars of a "rejection of any form of dualism" and "non-substantial philosophy" as unique characteristics of the Kyoto school or "logic of the East". My arguments are based on examining how linguistic differentiating articulation and narrative rendering that perform a fundamental role in human cognition are at work in definition of "emptiness" (sūnyatā) too. Thus emptiness is not completely empty; being certain philosophical identity it can be articulated only by differentiation from other identities, and thus different is included in it. Nishitani needed logocentric modes of thought, as a dialectical (m)other for constructing his sūnyatā ontology. Accordingly, the realms that are considered to be secondary or derivative (i.e. sensual and rational, or linguistic representations) appear to be the condition for constituting the primary (suchness of things, sūnyatā). Considering universal mechanisms of the articulation of values I am also asking whether sūnyatā paradigm indeed is so fundamentally different from Western paradigms centered on idea, God, or a rational subject as Nishitani wants to think. Since we find a clear hierarchical differentiation into truth and illusion, authentic and inauthentic modes of thought and time, and initial and derivative ontological realms, features of "strong thought" (in sense of Vattimo) are evident in his work. I am also suggesting, that possibly by considering not sūnyatā or "idea" but human languages as a universal "house of being", we would be able to "empty" discourses of radical difference and uniqueness, and in this way become post-nationalistically modern. Philosophy, in order not to turn into a onesided ideology, should reflect on its mythological and narratological conditions, i.e. dances on certain semiotic axes. From such a perspective, the gravitational trajectory of human thought, longing for conjunction with the absolute, defined either as God or as sūnyatā, will seem similar rather than different.

Keywords: Semiotics, Buddhism, Śūnyatā, differentiation, dialectics, intentionality. 


\section{Introduction}

Linguistic articulation and narrative rendering perform a fundamental role in human cognition. According to Cassiner, "all the concepts of theoretical knowledge constitute merely an upper stratum of logic which is founded upon a lower stratum, that of the logic of language" (p. 28). From this perspective, noesis and noema are never directly given, but inseparable from semiosis (process of cognition mediated by linguistic or non-linguistic signs) and seme (unit of the process of signification). The semiotic approach, which aims at finding the fundamental mechanisms of the articulation of meaning in texts, could be applied to analyze philosophical concepts as well; revealing how the "lower stratum" (i.e. principle of differentiation) is manifested in the higher stratum (i.e. concrete philosophical narratives) ${ }^{1}$ could enable fruitful comparative hermeneutics and shed new light on old problems.

The intention to establish certain fundamental centers and subordinating or hiding the peripheries as insubstantial is a characteristic of "strong" metaphysical or mythological narratives. We might consider that in strong metaphysics a "paranoid semiotic regime" or "a gliding atmosphere into which the slightest incident may be carried" is at work (Deleuze and Guattari p. 120). Does the metaphysics of śünyatā avoid such a regime?

In this article, invoking the phenomenological approach and some general principles of structural semiotics, I would like to examine critically and reveal some aporetic aspects of Nishitani's interpretation of the Buddhist concept of śünyatā. At the same time, I would like to consider some universal mechanisms of the articulation of values that are at work in "the logic of the East" as well. My central claim is that in Nishitani's philosophy, which is manifested most systematically in his Religion and Nothingness, structures of "strong" metaphysics are evidently at work. Thus, deeply ingrained claims among scholars of a "rejection of any form of dualism" and "non-substantial philosophy that radically redefines our notions of god, self and history" (Kopf p. 161) as unique characteristics of the Kyoto school or "logic of the East" might be seriously questioned.

In Religion and Nothingness, we can find several constantly operative semiotic axes that span various areas of philosophy and articulate Nishitani's position. The fundamental terms of these axes can be summarized as follows:

a) Ontological semiotic axis: relative being - absolute nothingness (śünyatā);

b) Epistemological semiotic axis: cogito (representation) - mushin (manifestation of things "as they are" in their "home-ground" position);

c) Religio-mythological semiotic axis: an absolute as an omnipotent transcendent person - an absolute that is inseparable from a concrete being;

d) Temporal semiotic axis: teleological, linear or cyclical time - totality of times, time as a "monad of eternity". 
e) Soteriological semiotic axis: nihility - śūnyatā;

f) Finally, there is a clearly articulated topological and axiological axis: the West - the East (or Japan).

What is the configuration of these terms and how are their dialectical relationships solved in Nishitani's Religion and Nothingness?

\section{Śūnyatā as ontological center}

In order to grasp the identity of a philosophical standpoint, it is helpful to identify its "enemy." 3 One of the most important constantly discussed "enemies" of Nishitani and other representatives of the Kyoto school are Kant and Hegel, who are considered the consequence and accomplishment of the Western evolution of philosophy. Nishitani clearly defines the position of German idealism as representation (p. 120). Critically reflecting on Kantian postulates of phenomenal appearance (see especially pages 12930 ), Nishitani gives us hope to touch the home-ground (もと) of being. Phenomenological descriptions of home-ground experience and differentiating it from what is not considered the home-ground are the most important axis in the narrative of Religion and Nothingness. An authentic mode of being is defined as the opposite of representation; existentially it is realized in a state of selflessness (muga無我). Nishitani assumes that Western philosophical idealism and scientific materialism are identical, because both of them are representation-based modes of thinking; in both of them there is a fundamental disjunction between subject and object in which subject performs an active role of representer. The metaphysics of will, manifested especially in Nietzsche, with all its modern consequences such as nihilism, emerges from this fundamental disjunction. The opposite of this mode of being is the Buddhism-based metaphysics of emptiness (s'ünyatā). Thus the substance manifested as representation in subject-consciousness is contrasted with the substance as non-representation in subject-consciousness. As Nishitani puts it (p. 125), "On the field of emptiness, substantiality is an absolutely non-substantial substantiality. . . . The eidetic form of a thing is truly form only when it is one with absolute non-form."

The most important intention of Nishitani's metaphysics is the revelation of the ontological fundamentality of siunnyatā over being and representation. In a manner similar to Heidegger, he reflects on the finitude of human being. Since death waits just over the horizon, authenticating existence is considered a simultaneous span of horizons of being and death; thus "double exposure is true visions of reality" (pp. 50-51).

The source of the representational mode of being is "pure experience," in which the subject still has not taken the active role of representor. In Religion and Nothingness, Nishitani focuses not so much on the phenomenology of 
experience as on defining the authentic mode of existence. Its opposition is "being" established by scientific "abstractness and universality" (p. 81), which pretends to be "the whole of truth" (p. 78). Science belongs to infinity, which people try to master through mathematically represented laws of nature; science reduces the totality of being and existence to a blind play of anonymous powers. ${ }^{4}$ Distinct from science, religions are oriented to an existential union with the absolute. The nihilistic incompatibility between religion and science, between the longing for the absolute and the indifference of nature treated in scientific manner as pure materiality, is inherent in the lives of contemporary humans. In the mind penetrated by nihilism however, the aspect of longing for true being remains. Accordingly, the distinction and disjunction between being and nothingness remains, and the "double exposure" is therefore not sufficiently realized. As distinct from nihilism, in the standpoint of śünyata nothingness is not the opposition of being any more. Śünyatā is defined as an inescapable abyss to which everything considered as "being"--science, representation or self--belong. The standpoint of śünyatā is existentially realized as ekstatic fall (datsuji 脱自) into that abyss. Since this "transcendence does not entail withdrawing off to some transcendent 'thing' called emptiness or nothingness" (p. 97), Nishitani considers it as the transcendence of the representational mode of being and thinking. Only in this mode is existence fully authenticated and thus "held suspended in nothingness, appears as a standpoint of truly subjective self-existence" (p. 98).

Śunyatā is treated as an ontological background from which both sensual and rational forms of experience emanate. Nishitani illustrates this schematically (see RN p. 141 or NKC pp. 159-160). Two concentric circles drawn around a point in the middle illustrate sensual and rational representations that are treated as apparitions, whereas the central dot is treated as an initial and thus authentic mode of perception, "a nonobjective way of being-in-the-middle" (pp. 141-42), the "home-ground."

The "being" of Western philosophy always implies secondary modes, i.e. representations, and thus the center of the ontological system "is always seen from the circumference" (p. 144). On the other hand, nihilism is treated as endless dispersion of representations or solipsistic pluralism that cannot be centered on any logos (see p. 143). Being and representation, noumena and phenomena, are always in a confrontational relationship that can be solved only from the standpoint of śünyatā, at which, as Nishitani suggests, they merge into one.

Nishitani claims, seemingly having in mind Hegel's concept of the absolute, that śünyatā cannot be treated as an abstraction (RN p. 146). From the standpoint of śunyata, the multiplicity of being cannot be reduced to intellectually contemplative unity (RN p. 144). The experience of things in their home-ground mode cannot be described as "all in one", i.e. as an 
intellectual span of polarities that results in an abstract vision of totality. The standpoint of śunnyatā is possible to realize only as a sensual concreteness in which "the mode of being of things in their selfness appears in the return from the circumference (namely, from the fields of sensation and reason) to the center... a center that is only center and nothing else" (p. 146). The center is equated to the suchness of things, whereas the circumference is equated to intellectual speculation or a sensual network. Yet this suchness (śünyatâ) also requires that it "is not reduced to a One" but be open to multiple perspectives (RN p. 146).

However, if we agree with Heidegger (p. 31) that "ontology is possible only as phenomenology," i.e. as experiences and the systematizing of experiences from the standpoints of certain monads, is it not true that the definition of the paradigmatic mode of experience and differentiating it from illusionary modes of experience contradict Nishitani's affirmation of multiplicity? From the phenomenological point of view, does the experience of śünyata not turn into ideality, i.e. the paradigmatic mode of experience? In this way, movement on the semiotic axes becomes centered and onedirectional in Nishitani's scheme. Ontologically and epistemologically only the centrifugal move is considered initial, whereas soteriologically only the centripetal move, from representation towards "home-ground," is considered authentic. Emanation from the ideal substance ("an absolute center, situated at the center of all things" RN p. 147) and return to it are characteristic of all "strong" and centered ontologies, which Nishitani himself criticizes. A pluralistic, "will-to-power"-based contemporary paradigm, which Nishitani finds existentially problematic, is confronted with a new metaphysical system and a new integrator: śünyată. However, in terms of mythological structure, is Nishitani's paradigm indeed fundamentally different from paradigms centered on idea, God, or a rational subject? The center of the system here turns into non-representation or rather contra-representation. However, contra-representation can be articulated only in regards to representation. Because emptiness or infinity function as a negation of finite and represented, negation is a way of being dependent on the negated, ${ }^{6}$ and this principle is operative on all levels of Nishitani's ontology and epistemology. Benveniste elucidates the structure of interdependency in a noetic-semiotic network as follows: "the characteristic of linguistic negation is that it can cancel only that which is uttered, that it must grant explicitly in order to suppress, that a judgment of non-existence has also necessarily the status of a judgment of existence. Thus negation is first of all admission."7

In a similar way, śünyatā cannot avoid the intentional-linguistic continuum in which any identity can be articulated only by differentiation from other identities, and thus different is included in any constitution. Thus, Nishitani's scheme can be turned upside down; the realms that are considered to be secondary or derivative (i.e. sensual and rational, or linguistic representations) 
appear to be the condition for constituting the primary or authentic (suchness of things, śünyatā). In this way the ideal of śünyata as a hierarchically higher substance isolated from the whole intentional-linguistic network seems to be the weakest aspect of Nishitani's ontology.

There is a moment in Nishitani's argumentation that contradicts the aforementioned one-directional emanation scheme, however. For describing the dynamics of his ontological system, Nishitani uses the term "circuminssesional interpenetration" (回互的相入 egoteki sonny $\bar{u}$ ): “"a system of circuminssesion has to be seen here, according to which, on the field of siunyatā, all things are in a process of becoming master and servant to one another. In this system, each thing is itself in not being itself, and is not itself in being itself. [...] This way that everything has of being on the home-ground of everything else..." (RN p. 149).

Cirsuminssesional interpenetration is a paraphrase of the Buddhist concept of co-dependent origination (sanskr. pratitya-samutpāda, jap. engi 縁起). The question is why is this circuminssesionally dialectic structure of emergence not applied to the highest universal, i.e. the śünyatā itself, and why is śünyat $\bar{a}$ considered a sufficient background resting just on itself? In the application of this principle to siunnyata, not only would representational modalities belong to an anonymous "home-ground," but vice versa as well; not only would the seeing be determined by the seen, but such a way of seeing as a paradigm would appear to be determined by the transcendental a priori network to which eye and way of seeing belong. Nishitani hides the inevitable transcendental aspect of phenomenal constitution, which to him looks too Kantian and Western. The eye, indeed, at certain moments does "not see itself," but the eye is always localized in the body and mind with their history and temporal totality, which is always brought into "seeing" and which contaminates the purity of seeing. As Hegel puts it, "it is only sense-certainty as a whole which stands firm within itself as immediacy" (1977: 62). A similar standpoint can be found in Derrida's critique of Rousseau's "mirage of the thing itself, of immediate presence, of originary perception." According to him, "Immediacy is derived. That all begins through the intermediary is what is indeed "inconceivable [to reason]" (1974: 157).

Nevertheless, sometimes Nishitani's admits that śūnyatā is not "natural" immediacy, but "It is drawn into the self itself by the subject that views the self as empty" (p. 151); or "It is only through making [italics - R.M] this non-objective self in itself . . . a home-ground that the self as subject becomes possible" (RN p. 155). ${ }^{9}$ We can see from these that not only Being emanates from śūnyatā, but also śünyatā itself becomes possible only through reflection. Considering the aspect of śünyatā's phenomenal givenness, we should ask whether this philosophical standpoint is indeed so far from Kantian hinneindekt (see RN p. 111, 134) or Hegelian teleology of self-consciousness as Nishitani wants to present it. 


\section{Śūnyatā as epistemological center}

In the paradigm of German idealism, what humans consider Being is a representation in the transcendental realm (see Nishitani's discussion on pages 142-44). Human beings can also grasp and establish the self only by representation. Thus the highest level of consciousness in this paradigm is noesis noeseos: self-contemplative thought. Centering the totality of being on representation, German idealism continues the tradition of Western metaphysics in which subject "thinks into" objects; in this way scientific objectivity or philosophical substances are possible. Realization of the fundamental gap between noumena and transcendental "human, only human" spheres leads to nihilism that for Nishitani, as well as for Nietzsche, is an accomplishment of the Western philosophical stance. Nihilistic "great doubt" can however open an absolutely different existential perspective. Nishitani's soteriological scheme is reminiscent of Neo-Platonist models. Ordinary existence and relative nothingness (i.e. nihilistic standpoint) emerge from and are perfected in absolute nothingness $\left(s^{\prime} \bar{u} n y a t \bar{a}\right)$. As distinct from Western models, this nothingness is not an intentional object but rather an ekstatic transcendence of intentionality. The standpoint of śünyatā is treated as a radical affirmation of nihility, which is existentially realized by nullifying the self. Nishitani claims that in śünyat $\bar{a}$ mode there "is no distinction here between the phenomenon and the thing-initself" (p. 138). This experience cannot be centered neither in noumena nor phenomena, because this "is not cognition of an object, but a non-cognitive knowing of the non-objective thing in itself." Accordingly in this standpoint, "we cannot speak of a 'knowing self'. We cannot say 'self' and so neither can we say "know"' (p. 140). Epistemological hierarchy and unidirectional emanation trajectory, which reflect the ontological model discussed above, can be especially seen in the following quotation (p. 179):

"'Meaning' is something abstracted from out of this living co-projection between mind and koto: an abstraction in which mind and koto stand in some conceptually 'ideal' correlation. [...] At the bottom ... lies the dimension of the elemental encounter with koto. It is here that meanings and intellectual cognition are constituted. [...] A koto, as some matter seen objectively or as the spoken word, is, along with its ratio or meaning, already divorced from reality. We have merely a mirror image of reality projected onto the dimension of the intellect."

Nishitani tries to argue that the śūnyatā mode of mind is neither objective nor representational; in this sense the śünyata mode is comparable to prethematized intentionality. However, how can this mode of mind be made into a paradigm, i.e. into the beginning and perfection of any cognitive activity, without a dialectical reflection and thematization as illustrated in Nishitani's teleological schemes? Suares's (2011) study convincingly shows how Nishitani, as well as the other most important representatives of the Kyoto school 
(Nishida and Tanabe) borrowed many architectonic elements from Hegel's dialectics, although Hegel's dynamic absolute received a biased interpretation as being limited only to rationality and monadic subject. Opposing Hegel's identification of the real and rational, Nishitani presents the standpoint of śünyata as "more real than anything that is real" (p. 183), and in which "the essence of ego is not of the ego". To formulate such a paradigm of mind, rational contemplation is unavoidable, however. Thus, "prajna wisdom," i.e. "the knowing of not knowing," is in any case positioned by subject. ${ }^{10}$ In this way, Nishitani's "more real," nevertheless becomes "contaminated" by rational. Accordingly, the interpretation of the Kyoto school's paradigm as fundamentally different from Hegel and German idealism might be questioned.

The interpretation of the transcendental realm as secondary and derivative also brings aporetic aspects to Nishitani's concept of time.

\section{Śūnyatā as temporal center}

The concept of time discussed in Religion and Nothingness resonates with Dōgen's consideration on the interconnectedness of time ( $u j i$ 有時), Nishida's “eternal now” (永遠の今 eien no ima), and Husserl's investigations of timeconsciousness. Eternal now comprises the infinity of the past and the infinity of the future. It contains in itself all the horizons of time, and thus every instant of time can be called a "monad of eternity" (RN p. 266). The antipodes of such instants of time are temporalities of the "Will of God, eschatology, Eternal Recurrence, Will to Power, time without beginning or end, infinite drive" ( $p$. 236). In all these modes of time, Nishitani finds the aspect of representation, i.e. temporalization from the standpoint of substantialized and autonomous subjectivity, either as a transcendental being (God) or as human. Even in Heraclitus and Nietzsche's ontologies of becoming, time is not fully authenticated since "They do not contain the other-centeredness by which they become 'empty' and make all others their master" (p. 265). In Nishitani's concept of time, as in ontology and epistemology, we can see a clear hierarchical scheme of emanation. Linear and cyclic modes of time are derived and subordinated to time as a "monad of eternity"; thus "human history is a world about men whose bodyand-mind has not fallen away, who wander continually in illusion, ignorant of the true path" (p. 201). Like the realization of śünyatā, the authentication of time is possible only in a mode of "dropping body-and-mind." In this mode, the totality of time manifests itself as absolute determinism, which is related to the Buddhist concept of karma (see p. 249). Accordingly, authenticated existence is equaled to fatal acceptance of this karmic dependency, which turns into freedom: "Karma is freedom determined by causal necessity within the whole infinite nexus, a freedom of spontaneity in 'attachment' and, therefore, a freedom totally bound by fate" (ibid.). 
We could ask once again why Nishitani does not apply circuminssesional dialectics to his highest universal of time. Is it because the "monad of eternity" is fundamentally dialectic in itself, and no further dialectical opposites are possible? However, any conceptual unity becomes a position that is implied by and implies dialectical others. From a semiotic point of view, which in many aspects is in total agreement with the Buddhist concept of co-dependent origination, neither phenomenon can be grasped singly; relationship with the other is accordingly primal in regard to any conceptual term (see Greimas 1987). In this way, the constitutional basis of any substance is its relationship with another substance or non-substance. Negation is the mode of dependency on the negated. From such a perspective, the hierarchical temporal emanation trajectory can be also turned upside down, and not only inauthentic linear times, but total śünyatā time, paraphrasing Nishitani (p. 265), could be "emptied," making all other times its master.

Being a network of intentionalities, time is inseparable from transcendental constitution. In this way Nishitani is right in saying that "it is the self as a master and non-ego that brings time to the fullness of time, or in other words, brings its own self-being to fullness" (p. 197). However, if it is the self that brings time to fullness, i.e. temporalizes and conceptualizes it in a certain way, śunnyata time is also a mode of representative temporalization and in this way is not different from other, "inauthentic" temporalities. ${ }^{11}$ Nevertheless, Nishitani hides this aspect and clearly differentiates authentic and inauthentic modes of time, relating the essence of time to the rather impossible ideal of non-intentionality, since, as I tried to argue above, the formulation of the ideal of non-intentionality is already intentional and textual. Tremblay (p. 174) puts the problem of Nishitani's considerations about time as a question: "how is it possible to think the other of time without this other being, on the level of its essence, a part of time itself?" In initial time, as in genuine initial emptiness, there should already be "the subject that views the self as empty" (RN p. 151). Human ordering (i.e. "inauthentic" representational modalities) belongs to an anonymous, hyletic field, to the body, which extends to the noumena and includes their traces in any noetic constitution. But all these "authentic" and primary modalities can emerge only as intentional content, i.e. as semiosis and as a text. In this way it becomes natura naturata, the mode of human ordering.

\section{Strata of semiosis and Śūnyatā}

Some aspects of Robert S. Corrington's considerations in A Semiotic Theory of Theology and Religion could be useful for examining Nishitani's paradigm in a new light. Corrington distinguishes four correlating layers of semiosis: "actual infinity," "open infinity," "prospective infinity," and "sustaining infinity." In Spinoza's terms "actual infinity" is natura naturata, the totality 
of signs and orders accessible to human cognition. In actual infinity there is no fundamental difference between active, waking intentionalities and oneiric, passive intentionalities. This mode is the most usual in human everydayness. Thus, the actual infinite is "the semiotic thickness and mobility of the world of signs, ever moving to new configurations. [...] The most simple repetition is still a repetition within a new contour, a new nexus that changes the meaning of that repetition" (Corrington p. 101).

This thickness can be turned into a clearly differentiating reductive mode, open infinity. In this mode, "the principle of individuation receives its maximal expression" and "[o]ne sign must differ from another, indeed, from all others (again in some respect), if it is to be a sign at all" (p. 109). "Open" infinity could be defined as contra-entropy that works either consciously or unconsciously. Scientific objectivity and philosophical substances, as well as artistic individualities, could be considered manifestations of this regime.

Actual and open infinities in turn correlate with the prospective infinite, which can be grasped only in comparison to the actual infinite: "If the actual infinite is represented by the image of the plentiful stream, the prospective infinite is represented by the image of the bed within which the stream moves [...] Or, using astronomical comparisons, the actual infinite will be represented by stars, planets and stellar matter, while the prospective infinite will obtain as a kind of gravitational pull within a specific system" (p. 104). If actual infinity could be compared with images of dreams and their logical or illogical narrative sequence, the prospective infinite would be the atmosphere of that dream. However, similar to unconsciousness, which can be brought to the surface only through consciousness and symbolic narrative rendering, prospective infinity is not autonomous from actual and open infinities. Like the unconscious, which could be defined as omni-temporal accumulation of all the experiences that condition present intentionality, this level nevertheless can be grasped only from the perspective of consciousness. Thus, according to Corrington, "[i]n the form of assertion: no actual infinite without its own prospective infinite, no prospective infinite without its own body of signs" (p. 104).

"Ordinary" discursive intentionality that questions philosophy often considers hyletic bodily modalities as initial background, which brings us back to the things themselves. However, as argued above, postulating something as background is possible only from the perspective of the "derivative" foreground, i.e. in the discursive and differential continuum. The aspect of linguistic mediation is well acknowledged by later Heidegger, who considers language a "house of being" that brings Being to beings. However, despite the application of the same principle of mutuality, in the final postulates Nishitani introduces asymmetry and hierarchy. In this way, actual and open infinities (ordinary intentionality, linear time) become subordinate to provisional infinity (nonintentionality, total time). "Gravitational pull" is however hardly possible "without stars, planets and stellar matter." In a similar manner, defining the 
śunnyatā, which as Nishitani believes lies beyond representation, ${ }^{12}$ is actually dependent on representational modes. Thus, Nishitani and Nishida's philosophical standpoints could be considered radical empiricism, which forgets, however, that it "employs the words to be. Empiricism is thinking by metaphor without thinking the metaphor as such" (Derrida: 138-139).

Nishitani longs for absolute conjunction with things (koto), "homeground," which as he thinks was lost in the hypostasis of representative thinking and can be regained only in the standpoint of śünyatā. It seems that he expects, speaking in terms of Lacan, to achieve connection with "the Real" there. However, the Real, which Corrington calls sustaining infinity "is not directly relevant to any of the traits of signs or sign systems, even as their anti-signs or anti-systems [...] is not 'concerned' with surrounding and empowering particular signs or systems, but with enabling them to be at all... It does not sustain what lies 'below' it, but lives horizontally, as it were, in the world of innumerable signs and sign systems" (p. 111). "It sustains all of the innumerable orders of nature natured, whether semiotic or virtually semiotic" (p. 112).

About exterior, we cannot speak otherwise than in terms of interior. We can give some predicates for exterior and in this way entrench it intentionally in the interior. We can try to define fundamental existential structure and expect that "the Real" was achieved, but nevertheless it will remain in the semio-noetic continuum as symbolic or as anti-symbolic. However, if this "ground" "lives horizontally in the world of innumerable signs and sign systems," śünyatā as "encounter with koto" or "the Real," should not be a feature of a particular existential standpoint or culture, but our existential conditio sine qua non. It sustains and appears not only in pre-thematized intentionalities but also in thematized intentionalities; thus, neither intentionality lacks this.

\section{Concluding remarks}

For Parmenides and Plato, nothingness and chaos were necessary dialectical (m)others to construct their ontologies of being and cosmic order. In the same way, Nishitani needed logocentric modes of thought, as a dialectical $(m)$ other for constructing his śünyatā ontology. In both cases clear differentiation and hierarchy result in certain substance-centered metaphysical systems, even though the thinkers of the Kyoto school interpreted such metaphysics as characteristic only of the West. More broadly, in ancient Buddhist metaphysics, human cognitive ability of operating in noemas and having some sense of stability was necessary for constructing the metaphysics of insubstantiality and corresponding soteriological modes. The same dialectical scheme was operative in the formation of Zen Buddhist ideology, in which, according to Faure (1991:75), "[t]he negation of the symbolic became itself largely 
symbolic. It turned into an ideology that, while taking the opposite course from traditional mediations, was entangled in the same aporias."

The variety of possible orders in Nishitani's philosophy is clearly divided into truth and illusion, authentic and inauthentic modes of thought and time, and initial and derivative ontological realms. So, is the "logic of the East" indeed non-dualistic and non-hierarchical and thus unique? According to Zhang (p. 395), "since the oriental way of thinking is supposedly more intuitive than analytical and keeps the totality of the world untouched by the process of logical abstraction, this contrast between intuition and expression already includes the East in the tradition of the metaphysics of presence. Logocentrism, therefore, does not inhabit just the Western way of thinking; it constitutes the very way of thinking itself." In Buddhist monistic schemes, higher-level dualism and hierarchy are at work. Being-sive-Nothingness, or totality, has its inauthentic other as well, i.e. non-totality, or being and nothingness as separate substances. Thus, according to Suares ( $\mathrm{p}$. 127), "Nishitani's philosophical discourse does not offer a breakthrough in logic, comparable to that which it never tires of depicting."

The most aporetic aspects of siunyatā metaphysics emerge when the attempt is made to present śünyatā ontologically as authentic Being (i.e. nothingness), forgetting the aspect of its transcendental constitution, which makes all the absolute grounds, "human, all too human." In this sense, Hegel (1991: 139) probably was right in claiming that "[n] othingness, which the Buddhists have made the beginning principle for everything and the final goal and the ultimate end of everything, is this same abstraction."

Possibly by considering not śünyatā or "being" but language and semiotic orders as a universal background, we would be able to "empty" discourses of radical difference and uniqueness, and in this way become post-nationalistically modern. Particular languages are indeed to a certain degree untranslatable. But, beside this dimension, it would be one-sided not to see universal building structures that are common for many "houses of being". It is hard to believe that these organic mechanisms of differentiation would bypass any human mind. Accordingly, philosophy, in order not to turn into a one-sided ideology, should reflect on its mythological and narratological conditions, i.e. dances on certain semiotic axes. From such a perspective, the gravitational trajectory of human thought, longing for conjunction with the absolute, defined either as God or as śünyatā, will seem similar rather than different. However, as Heisig notices (2009: 328), "[t]here is no question here of a lasting peace, a harmony of opposites, without cutting the very heart out of Nishitani's philosophy." Demarcations between the logics of the East and the West and considering the former superior, as in Nishitani's ambivalent wartime sayings about the role of śünyatā-based Japanese civilization in the world, could also testify to some underlying political dimensions. Yet, putting politics aside, it remains necessary to re-examine the tendency of interpreting the Kyoto school philosophy as purely experience-oriented, completely unique, and non-dualistic. 


\section{References}

Cassiner, E., 1953. Language and Myth. Tr. by Suzanne K. Langer. Dover Publications Inc. NY.

Corrington, R. S., 2000. A Semiotic Theory of Theology and Religion. Cambridge University Press.

Deleuze, G., Guattari F., 2005. A Thousand Plateaus: Capitalism and Schizophrenia. Translation and Foreword by Brian Massumi. University of Minnesota Press.

Derrida, J., 1978. Force and Signification (pp. 3-30) in Writing and Difference. Tr. Alan Bass. Routledge \& Kegan Paul, London.

Eco, U., 2012. Inventing the Enemy: Essays. Houghton Mifflin Harcourt Press.

Faure, B., 1991. The Rhetoric of Immediacy: A Cultural Critique of Chan/Zen Buddhism. Princeton University Press.

Faure, B., 1993. Chan Insights and Oversight: An Epistemological Critique of the Chan Tradition. Princeton University Press.

Greimas, A. J., 1987. On meaning: Selected Writings in Semiotic Theory. Tr. By Paul J. Perron and Frank H. Collins, foreword by Frederic Jameson; introduction by Paul J. Perron. Minneapolis: University of Minnesota Press.

Heidegger, M., 1996. Being and Time. Tr. Joan Stambaugh. SUNY Press.

Hegel, G. W. F., 1977. Phenomenology of Spirit. Tr. A. V. Miller with Analysis of the Text and Foreword by J. N. Findlay. Oxford University Press.

Hegel, G. W. F., 1991. The Encyclopaedia Logic (with the Zusätze) (Part I of the Encyclopaedia of Philosophical Scineces with the Zusätze). A New Translation with Introduction and Notes by T. F. Geraets, W. A. Suchting, and H. S. Harris. Hackett Publishing Company, Inc. Indianapolis/Cambridge.

Heisig, J. W., 2009. Nishitani Keiji and the Overcoming of Modernity (1940-1945). In Frontiers of Japanese Philosophy 6: Confluences and Cross-Currents (p. 297-329), ed. Raquel Bouso Garcksa and James W. Heisig. Nanzan Institute for Religion and Culture.

Heisig, K., Maraldo (eds.) Japanese Philosophy: A Sourcebook. University of Hawai'i Press.

Kopf, G., 2011. Language Games, Selflessness, and the Death of God: A/Theology in Contemporary Zen Philosophy and Deconstruction. In Japanese and Continental Philosophy: Conversations with the Kyoto School. Ed. by Bret W. Davis, Brian Schroeder, and Jason M. Wirth. Indiana University Press (p. 160-178).

Lotman, Y., Ivanov V.V., Pjatigorski J. M., Toporov V.N., Uspenskij B.A. 1998. Theses on the Semiotic Study of Cultures. Tartu: Tartu Semiotics Library 1. Nishitani, Keiji, 1982. Religion and Nothingness. Tr. Jan Van Bragt, University of California Press, Berkeley. Abbreviation: RN

Nishitani, Keiji, (1986-1995)『西谷啓治著作集』 [Collected works of Nishitani Keiji], Tokyo: Sōbunsha. Vol 10. Abbreviation: NKC

Suares, P., 2011. The Kyoto School's Takeover of Hegel: Nishida, Nishitani and Tanabe Remake the Philosophy of Spirit. Rowman \& Littlefield Publishers Inc. 
Tremblay, J., 2008. Hidden Aspects of Temporality from Nishida to Watsuji. In Frontiers of Japanese Philosophy 2: Neglected Themes and Hidden Variations, (pp. 160-176). Ed. Victor Sōgen Hori and Melissa Anne-Marie Curley. Nanzan Instutitute for Religion and Culture.

Vattimo, G., Rovatti, P. A., 2012.Weak Thought. Translated and with an introduction by Peter Carravetta. SUNY Press.

Zhang, Longxi, 1985. The Tao and the Logos: Notes on Derrida's Critique of Logocentrism. In Critical Inquiry 11: 385-398.

\section{Acknowledgement}

The author is very grateful to Canon Foundation in Europe which supported his research in Japan from April 2013 to March 2014.

\section{Endnotes}

1 The "generative trajectory" (parcours génératif) theory was developed in the semiotics of A. J. Greimas (see Greimas 1987) (an almost similar approach can be found in Lévi-Straus's studies of myths). According to him, discourses could be analyzed as the interplay of three levels of the articulation of meaning. In the narrative syntax level, we find a concrete text with concrete actors and situations. On the more abstract layer of discursive syntax, we find actants, i.e. certain standard standpoints or roles, for example subject and object, sender and receiver, and helper and opponent. On the most abstract layer, we find the linguistic and human cognitive ability-based principle of differentiation. Accordingly, on the narrative syntax level, texts look different, but in the more abstract levels we find universal principles and mechanisms at work.

2 The definition of "strong" metaphysics I derive from G. Vattimo's "strong thought" (pensiero forte). Its dialectical other is "weak thought" (pensiero debole), which characterizes a situation in which absolute foundations and irreversible values beyond the historical horizons are hardly possible (see Vattimo and Rovatti 2012).

3 About the necessity for any national, political or cultural unit to have an "enemy" or contraidentity, see U. Eco (2012). J. Lotman's considerations (1998) about role of "barbarian" in constituting the cultural cosmos would also be appropriate in this context.

4 See especially Religion and Nothingness part III chapter II.

5 Nishitani's hierarchical emanation ontology can be illustrated by this quotation: "On the field of śünyatā . . things . . a appear from the home-ground (elemental source) of their existence, from the selfness lying at their home-ground. This means that the sensible and rational forms of a thing recuperate original meaning as apparitions of the non-objective mode of being of the thing in itself, as the positions of that thing" (RN p. 146).

6 Hisamatsu Shin'ichi (see Heisig, Kasulis and Maraldo, Sources of Japanese Philosophy pp. 221-226) tries to define oriental nothingness as "beyond predication" and "nothing in the sense of a negative predication" (p. 222). It is hardly convincing however, since 
"being beyond" is already a predication. Moreover, 10 characteristics of "void" are later listed (p. 224), and authentic nothingness is defined in a traditional manner as an "awareness in which subject and object are one" (p. 223).

7 Benveniste, Emile. 1966-1974. Problèmes de linguistique générale. 2. vols. Paris: Gallimard. I: 84, quoted in Faure 1993: 197-8.

8 This concept is structurally similar to Nishida's absolutely contradictory self identity (zettai mujunteki jiko dōitsu 絶対矛盾的自己同一), which in turn could be considered a contemporary philosophical elaboration of ancient Mahāyāna Buddhist thought.

9 然もかかる非対象的な自己白体と、その非対象的な自覚「もと」にして初め て、主体としての自己も可能である (NKC vol 10. 宗教とは何か 174).

10 Suares ends his book on the Kyoto school and Hegelian legacy by quoting a passage from Nishida's Essence of Spirit (kokoro no hontai, from Nishida's collected works 5:451): "But absolute nothingness does not simply mean that there is nothing; it is rather the ultimate in noetic determination, it means the essence of spirit." He suggests that "Hegel himself would not have said it better" (Suares p. 193), but this is applicable to Nishitani's concept of śünyatā as well.

11 Tremblay's remark (p. 174) that illustrates the aporetic aspect of the initial-derivative hierarchy could be useful in this context: "rectilinear time is grounded on a boundless and transcendent openness which is directly beneath the feet of human beings, namely the bottom of the present. Nishitani comes to this conclusion after criticizing the traditional Christian conception of a merely transcendent God located beyond the world. It appears however that he maintains the transcendence, but reinterprets it in terms of infinite openness located 'below' the world. Regarding the representative schemes, it seems that there is little difference between the Christian conception and that of Nishitani."

12 "It is rather a mode of being that has nothing at all to do with our representations or judgments" (RN p. 127).

\section{About Author}

\section{Ramūnas MOTIEKAITIS}

He studied composition and musicology at Lithuanian and Norwegian academies of music. He pursued and completed his doctoral studies at the University of Helsinki (2011). During 2008-2010 with support of Japanese ministry of education, Motiekaitis worked as a researcher in Tokyo Musashino Academy of Music. During 2013-2014 with support of Canon foundation in Europe he continued research at Nanzan Institute for Religion and Culture in Nagoya, Japan. Currently Motiekaitis lectures on Japanese philosophy at Vilnius University and on aesthetics at the Lithuanian Academy of Music and Theatre. Research interests: semiotic theory of culture and philosophy, metaphysics of Buddhism, philosophy of the twentieth century, Japanese aesthetics and its contexts.

ramunas_motiekaitis@hotmail.com 